\title{
BMJ Open Association between social isolation and depression onset among older adults: a cross-national longitudinal study in England and Japan
}

\author{
Taiji Noguchi (D) , ${ }^{1,2}$ Masashige Saito (D) , ${ }^{3}$ Jun Aida (D) , ${ }^{4,5}$ Noriko Cable (D) ${ }^{6}$ \\ Taishi Tsuji (D) , 7,8 Shihoko Koyama (D) , ${ }^{9}$ Takaaki lkeda (D) ,10,11 Ken Osaka (D) ,11 \\ Katsunori Kondo (iD) 8,12
}

To cite: Noguchi T, Saito M, Aida J, et al. Association between social isolation and depression onset among older adults: a cross-national longitudinal study in England and Japan. BMJ Open 2021;11:e045834. doi:10.1136/ bmjopen-2020-045834

- Prepublication history and additional material for this paper is available online. To view these files, please visit the journal online (http://dx.doi.org/10. 1136/bmjopen-2020-045834).

Received 13 October 2020 Revised 19 February 2021 Accepted 22 February 2021
Check for updates

(C) Author(s) (or their employer(s)) 2021. Re-use permitted under CC BY. Published by BMJ.

For numbered affiliations see end of article.

Correspondence to Mr Taiji Noguchi; noguchi.taiji0415@gmail.com

\section{ABSTRACT}

Objective Social isolation is a risk factor for depression in older age. However, little is known regarding whether its impact varies depending on country-specific cultural contexts regarding social relationships. The present study examined the association of social isolation with depression onset among older adults in England, which has taken advanced measures against social isolation, and Japan, a super-aged society with a rapidly increasing number of socially isolated people.

Design Prospective longitudinal study.

Setting We used data from two ongoing studies: the English Longitudinal Study of Ageing (ELSA) and the Japan Gerontological Evaluation Study (JAGES).

Participants Older adults aged $\geq 65$ years without depression at baseline were followed up regarding depression onset for 2 years (2010/2011-2012/2013) for the ELSA and 2.5 years (2010/2011-2013) for the JAGES. Primary outcome measure Depression was assessed with eight items from the Centre for Epidemiologic Studies Depression Scale for the ELSA and Geriatric Depression Scale for the JAGES. Multivariable logistic regression analysis was performed to evaluate social isolation using multiple parameters (marital status; interaction with children, relatives and friends; and social participation). Results The data of 3331 respondents from the ELSA and 33127 from the JAGES were analysed. Multivariable logistic regression analysis demonstrated that social isolation was significantly associated with depression onset in both countries. In the ELSA, poor interaction with children was marginally associated with depression onset, while in the JAGES, poor interaction with children and no social participation significantly affected depression onset. Conclusions Despite variations in cultural background, social isolation was associated with depression onset in both England and Japan. Addressing social isolation to safeguard older adults' mental health must be globally prioritised.

\section{INTRODUCTION}

With population ageing, there is growing worldwide interest in social issues concerning older adults, including social isolation and the deterioration of physical and mental

\section{Strengths and limitations of this study}

- This is the first cross-national longitudinal study to examine the association between social isolation and depression onset in England, which has taken advanced measures against social isolation, and Japan, a super-aged society with a rapidly increasing number of socially isolated people.

- This study included a large sample of over 3300 individuals from England and 33000 individuals from Japan aged 65 years and older.

- A limitation of this study is that we cannot make direct comparisons because of variations in cohort follow-up periods and depression measurement.

- Another limitation is the use of social support for the evaluation of social contact so as to permit the use of the same social isolation assessment scale in both countries.

health. Defined as an objective state in where an individual has few close relationships or limited contact within a community, ${ }^{1}$ social isolation is recognised as a social determinant of health with relevance to mortality, ${ }^{2}$ cardiovascular diseases, ${ }^{3}$ dementia $^{4}$ and mental health. ${ }^{5}{ }^{6}$ Social isolation is a major risk factor for mental health problems in older age. Several systematic reviews have demonstrated that social isolation is associated with depressive symptoms, ${ }^{56}$ which, in turn, are correlated with unhealthy behaviours and reduced access to material resources. ${ }^{7}$ Depression, common in later life, is related to adverse health outcomes such as poor quality of life ${ }^{8}$ and functional disability. ${ }^{9}$ With the high current global burden of depression expected to increase further by $2030,{ }^{10}$ addressing social isolation is an important gerontological issue for protecting mental health among older adults. 
The impacts of social isolation on health may vary by country; this could be the result of differences in the social environments related to social networks within and outside the family. A recent study of older adults in England and Japan showed that social isolation is a common risk factor for mortality in both countries, with a greater impact observed in England; the results are discussed in terms of possible differences between societies that are highly connected and those that are not. ${ }^{11}$ In the UK, in recognition of the impact of social isolation on health and economic loss, the position of 'Minister of Loneliness' was established in 2018, and the country is taking a progressive approach to the elimination of social isolation. ${ }^{12}$ In contrast, Japan, now a super-aged society (more than $21 \%$ of the population aged 65 or above), ${ }^{13}$ is experiencing a rapidly increasing trend in the number of never-married persons and weakening community and neighbourhood relations, ${ }^{14}$ leading to a rise in the number of socially isolated individuals. ${ }^{15}$ In Japan, the proportion of people who rarely or never spend time with those close to them has been reported to be the highest among Organisation for Economic Co-operation and Development countries. In particular, this figure is much higher than in the UK, which has made advances in tackling social isolation (Japan $=15.3 \%$, UK=5.0\%) ${ }^{16}$ Owing to differences in social structures and the contexts surrounding social isolation, the impact of social isolation on depression is expected to vary across countries.

Furthermore, the health effects of social isolation may differ depending on the cultural context of social relationships. In East Asian countries, including Japan, there is a familial norm based on the traditional culture of filial piety, ${ }^{17}$ which is often contrasted with individualism in Western countries. ${ }^{18}{ }^{19}$ Based on this cultural background, Japanese social support networks may be kinship centred, which may be narrower than the types of social networks prevalent in other countries. ${ }^{20}$ However, there is a lack of consensus on the health effects of social relationships based on these cultural differences. A previous cross-national study showed that among English men, friendship-based social relationships had a significant impact on longevity, whereas among Japanese men, this impact was associated with family-based social relationships. ${ }^{21}$ In contrast, a study of older adults in the USA and Japan demonstrated that while relationships with children were associated with a low level of depression only in Japan, the presence of spouses was important in both countries, but more so in the USA. ${ }^{22}$ Another comparative study among adults suggested that social contact with friends benefited women's mental health in the UK but not in Japan. ${ }^{23}$ Thus, the family-oriented nature of East Asian societies does not automatically imply the health importance of family-based relationships, and the roles of individual components of social isolation (family, friends and others) in the mental health of older adults in each country remain controversial.

As the association between social isolation and depression is often described as bidirectional, ${ }^{24}$ longitudinal studies are needed to address temporality. However, previous cross-national comparative studies have employed only cross-sectional designs. ${ }^{22}{ }^{23}$ Therefore, using longitudinal data from both countries, the present study aims to investigate the association of social isolation with depression onset in England, which has taken advanced measures against social isolation, and Japan, a super-aged society with a rapidly increasing number of socially isolated people.

\section{METHODS}

\section{Sample}

This longitudinal study was conducted using data from two ongoing prospective cohort studies: the English Longitudinal Study of Ageing (ELSA) and the Japan Gerontological Evaluation Study (JAGES). The ELSA targets independent-living older adults aged $\geq 50$, while JAGES participants are community-dwelling individuals aged $\geq 65$ who are ineligible for long-term healthcare insurance benefits. ${ }^{25}$ Details of the ELSA and JAGES can be found elsewhere. ${ }^{2627}$ For the present analysis, we used the two waves of data that most closely corresponded with the timing of our study: wave $5(2010 / 2011)$ to wave 6 $(2012 / 2013)$ for the ELSA, and wave $1(2010 / 2011)$ to wave 2 (2013) for the JAGES. We harmonised the data by including older adults aged $\geq 65$, independent in activities of daily living, and without self-reported dementia. For analysis, respondents who scored above the cut-off point for depression on each measure in the respective cohort at baseline were excluded and we followed up the onset of depression for 2 years for the ELSA and 2.5 years for the JAGES.

\section{Depression}

Based on a previous cross-national study, ${ }^{28}$ depressive symptoms were measured both at baseline and follow-up using eight items from the Centre for Epidemiologic Studies Depression Scale (CES-D 8) in the ELSA ${ }^{29}$ and the Geriatric Depression Scale (GDS-15) in the JAGES. ${ }^{30}$ To identify possible depressive cases, the CES-D 8 cut-off was $\geq 4$ while that for the GDS- 15 was $\geq 5 .{ }^{31}{ }^{32}$ As previously mentioned, respondents with depression at baseline were excluded and we observed the onset of depression during the follow-up.

\section{Social isolation}

Social isolation levels were assessed using a modified version of the Social Isolation Index (SII). ${ }^{3-35}$ The index was computed with respondents given a point if they: (1) were unmarried or living alone, (2) had poor interaction with children (did not live with their children or had no one to provide emotional or instrumental social support), (3) had poor interaction with relatives (did not have immediate family members providing emotional or instrumental social support), (4) had poor interaction with friends (less than monthly contact or no friends who could provide emotional or instrumental social support) 
and (5) had no social participation (no participation in any social or religious groups). The total possible score ranged from 0 to 5 , with higher scores indicating greater social isolation. The participants were categorised into the following five groups based on their scores: $0,1,2,3$ and 4-5 points. We used the total score and the scores of the five subcomponents as predictive variables.

\section{Covariates}

The covariates included age, gender, educational attainment, household equivalised income, present illness, selfrated health, smoking and drinking. Age was categorised as $65-69,70-74,75-79,80-84$ and $\geq 85$. Based on the ages of respondents who had completed formal education, the age of final educational attainment was categorised as $\leq 15$ years, $16-18$ years and $\geq 19$ years. Household equivalised income was classified into quintiles. Present illness was classified as 'yes' or 'no' for cancer, heart disease and stroke. Self-rated health was dichotomised as 'poor' and 'good'. Smoking and drinking were dichotomised as 'never/past' and 'current'.

\section{Statistical analysis}

We analysed the ELSA and JAGES data separately because of differences in research design, especially sampling approaches. A longitudinal weight was applied to account for survey non-response for the ELSA but not the JAGES as its design does not allow it. First, we calculated descriptive statistics. Second, we conducted a multivariable logistic regression analysis to examine the association between SII score and depression onset and obtained ORs and 95\% CIs for depression onset. Model 1 was not adjusted for covariates while Model 2 was adjusted for all covariates. Additionally, we analysed the association between SII subcomponents and depression onset, adjusted for all covariates.

To mitigate potential biases resulting from missing information, we used the multiple imputation approach under the missing at random assumption. We generated 20 imputed datasets for the final analysis, which excluded those who met the exclusion criteria and did not respond to the follow-up surveys, using the multiple imputation by chained equations procedure and pooled the results using Rubin's rule. ${ }^{36}$

The significance level was set at $\mathrm{P}<0.05$. We used $\mathrm{R}$ (V.3.5.2 for Windows) for all statistical analyses.

\section{Patient and public involvement}

No patients were involved in the development of the research question, study design or data interpretation.

\section{RESULTS}

A total of 3331 ELSA respondents and 33127 JAGES respondents were included in the final analysis. Their baseline characteristics are presented in table 1 . The mean age (SD) was 73.6 (6.9) years for the ELSA and 72.4 (5.4) years for the JAGES. Regarding SII scores, the ELSA had the largest number of respondents with 0 and 1 points, while the JAGES had the largest number with 2 and 3 points. In the ELSA, respondents who were older, male, less educated, had a lower income, had heart disease, had poor self-rated health, smoked, consumed little alcohol and had higher baseline depressive symptom scores and higher SII scores. A similar trend was observed in the JAGES, but here, those who consumed more alcohol had higher SII scores.

Table 2 presents the description of social isolation and depression onset. At follow-up, 201 (6.0\%) ELSA respondents and 4456 (13.5\%) JAGES respondents exhibited depression onset. In both studies, higher SII scores were associated with an increased risk of depression onset. Regarding SII subcomponents, ELSA respondents who were unmarried or living alone were more likely to have depression, while this was the case with JAGES respondents with no social participation.

Table 3 depicts the association between SII scores and depression onset. Multivariable analysis showed that higher SII scores were associated with a higher risk of depression onset in both studies after adjusting for all covariates. In the ELSA, the OR of depression onset was significantly higher from a score $\geq 1$ point (OR [95\% CI] compared with zero points, one: 1.68 [1.02 to 2.75], two: 1.77 [1.03 to 3.05], three: 2.64 [1.37 to 5.12], $\geq$ four: 4.01 [1.43 to 11.22], $\mathrm{P}$ for trend $=0.015$ ). In the JAGES, as SII scores increased, the OR of depression onset gradually increased, reaching significance at $\geq$ three points (OR [95\% CI] compared with zero points, one: 1.10 [0.89 to 1.35 ], two: 1.15 [0.94 to 1.40 ], three: 1.28 [1.04 to 1.56 ], $\geq$ four: 1.48 [1.18 to 1.85$]$, P for trend $<0.001$ ). These results showed almost the same tendency as the complete case analysis without multiple imputation (online supplemental table 1 ).

Table 4 presents the associations of SII subcomponents with depression onset. In the ELSA, subcomponents were not significant, although poor interaction with children was marginally significant (OR [95\% CI]) with 'none' as the reference; unmarried or living alone: 1.13 [0.80 to 1.60], poor interaction with children: 1.55 [1.00 to 2.41], poor interaction with relatives: 1.24 [0.79 to 1.94], poor interaction with friends: 1.15 [0.77 to 1.71], no social participation: 1.22 [0.80 to 1.87]). In the JAGES, poor interaction with children and no social participation were significantly associated with depression onset after adjusting for all covariates (OR [95\% $\mathrm{CI}]$, with 'none' as the reference; unmarried or living alone: 1.11 [1.00 to 1.24], poor interaction with children: 1.09 [1.01 to 1.19], poor interaction with relatives: 1.04 [0.96 to 1.12], poor interaction with friends: 1.03 [0.95 to 1.11$]$, no social participation: 1.28 [1.17 to 1.40]). These results were similar to those obtained from the complete case analysis (online supplemental table 2).

\section{DISCUSSION}

To the best of our knowledge, this is the first cross-national longitudinal study of the association of social isolation with depression among older English and Japanese adults. Social 
Table 1 Respondents' baseline characteristics

\begin{tabular}{lllll}
\multicolumn{5}{l}{ ELSA $^{*}$} \\
\hline \multicolumn{5}{l}{ Social Isolation Index scoret } \\
\hline $\mathbf{0}$ & $\mathbf{1}$ & $\mathbf{2}$ & $\mathbf{3}$ & $\geq 4$ \\
\hline $\mathrm{n}=905$ & $\mathrm{n}=1049$ & $\mathrm{n}=596$ & $\mathrm{n}=216$ & $\mathrm{n}=49$
\end{tabular}

JAGES

$\begin{array}{llllll}(27.2 \%) & (31.5 \%) & (17.9 \%) & (6.5 \%) & (1.5 \%)\end{array}$

Social Isolation Index score†

\begin{tabular}{lllll}
\hline 0 & 1 & 2 & 3 & $\geq 4$
\end{tabular}

$\begin{array}{lllll}\mathrm{n}=1402 & \mathrm{n}=5981 & \mathrm{n}=\mathbf{9 7 2 3} & \mathrm{n}=8735 & \mathrm{n}=\mathbf{2 1 7 6}\end{array}$

$\begin{array}{lllll}(4.2 \%) & (18.0 \%) & (29.4 \%) & (26.4 \%) & (6.6 \%)\end{array}$

Age (years), (\%)

\begin{tabular}{|c|c|c|c|c|c|c|c|c|c|c|}
\hline $65-69$ & 41.0 & 36.4 & 29.9 & 27.6 & 28.3 & 38.6 & 40.5 & 38.0 & 37.0 & 35.8 \\
\hline $70-74$ & 26.1 & 28.3 & 28.8 & 29.3 & 23.6 & 32.1 & 32.5 & 31.6 & 31.0 & 30.4 \\
\hline $75-79$ & 20.9 & 17.5 & 19.3 & 15.8 & 20.4 & 19.2 & 18.3 & 19.5 & 20.3 & 21.9 \\
\hline $80-84$ & 9.1 & 12.2 & 12.5 & 14.5 & 15.5 & 8.3 & 6.7 & 8.3 & 9.0 & 8.8 \\
\hline$\geq 85$ & 2.8 & 5.7 & 9.5 & 12.8 & 12.2 & 1.9 & 2.0 & 2.6 & 2.7 & 3.1 \\
\hline \multicolumn{11}{|c|}{ Gender, (\%) } \\
\hline Men & 50.0 & 46.1 & 45.3 & 51.9 & 65.8 & 27.2 & 35.1 & 47.0 & 64.4 & 66.1 \\
\hline Women & 50.0 & 53.9 & 54.7 & 48.1 & 34.2 & 72.8 & 64.9 & 53.0 & 35.6 & 33.9 \\
\hline
\end{tabular}

Educational attainment (years), (\%)

\begin{tabular}{|c|c|c|c|c|c|c|c|c|c|c|}
\hline$\leq 15$ & 44.1 & 51.3 & 52.3 & 60.9 & 69.6 & 42.9 & 38.1 & 37.9 & 38.7 & 48.6 \\
\hline $16-18$ & 35.0 & 33.8 & 34.6 & 27.5 & 14.1 & 40.9 & 40.8 & 39.3 & 36.8 & 31.1 \\
\hline$\geq 19$ & 17.8 & 12.5 & 11.0 & 10.3 & 14.0 & 15.7 & 20.4 & 21.8 & 23.3 & 18.5 \\
\hline \multicolumn{11}{|c|}{ Household equivalised income, (\%) } \\
\hline $\begin{array}{l}\text { First quintile } \\
\text { (lowest) }\end{array}$ & 11.4 & 18.3 & 23.2 & 31.2 & 14.4 & 7.4 & 10.9 & 13.9 & 15.6 & 21.3 \\
\hline Third quintile & 20.9 & 21.8 & 18.9 & 19.5 & 27.1 & 22.5 & 30.6 & 30.3 & 30.6 & 28.0 \\
\hline Fourth quintile & 21.9 & 19.9 & 18.1 & 16.5 & 16.6 & 14.3 & 13.6 & 12.7 & 11.3 & 9.5 \\
\hline $\begin{array}{l}\text { Fifth quintile } \\
\text { (highest) }\end{array}$ & 22.7 & 15.0 & 12.7 & 8.3 & 12.4 & 31.5 & 22.5 & 19.2 & 16.8 & 12.9 \\
\hline Yes & 3.4 & 4.2 & 2.9 & 2.5 & 3.5 & 3.2 & 3.1 & 3.1 & 3.4 & 3.7 \\
\hline Missing & 0.1 & 0.0 & 0.0 & 0.0 & 0.0 & 5.8 & 5.7 & 6.1 & 6.5 & 6.6 \\
\hline
\end{tabular}

Heart disease, (\%)

\begin{tabular}{|c|c|c|c|c|c|c|c|c|c|c|}
\hline No & 90.7 & 86.9 & 88.4 & 88.3 & 77.3 & 91.0 & 91.2 & 90.8 & 90.1 & 89.7 \\
\hline Yes & 9.3 & 13.0 & 11.6 & 11.7 & 22.7 & 3.2 & 3.1 & 3.1 & 3.4 & 3.7 \\
\hline Missing & 0.0 & 0.1 & 0.0 & 0.0 & 0.0 & 5.8 & 5.7 & 6.1 & 6.5 & 6.6 \\
\hline \multicolumn{11}{|l|}{ Stroke, (\%) } \\
\hline No & 96.3 & 96.1 & 97 & 94.4 & 96.6 & 93.3 & 93.6 & 93.1 & 92.5 & 92.2 \\
\hline Yes & 3.7 & 3.8 & 3.0 & 5.6 & 3.4 & 0.9 & 0.8 & 0.8 & 1.0 & 1.2 \\
\hline \multicolumn{11}{|c|}{ Self-rated health, (\%) } \\
\hline Good & 86.4 & 79.9 & 78.8 & 75.4 & 71.3 & 92.0 & 91.7 & 90.6 & 90.2 & 87.2 \\
\hline Poor & 13.6 & 20.1 & 21.2 & 24.6 & 28.7 & 7.2 & 7.7 & 8.6 & 9.0 & 12.2 \\
\hline Missing & 0.0 & 0.0 & 0.0 & 0.0 & 0.0 & 0.8 & 0.5 & 0.8 & 0.8 & 0.6 \\
\hline \multicolumn{11}{|l|}{ Smoking, (\%) } \\
\hline
\end{tabular}




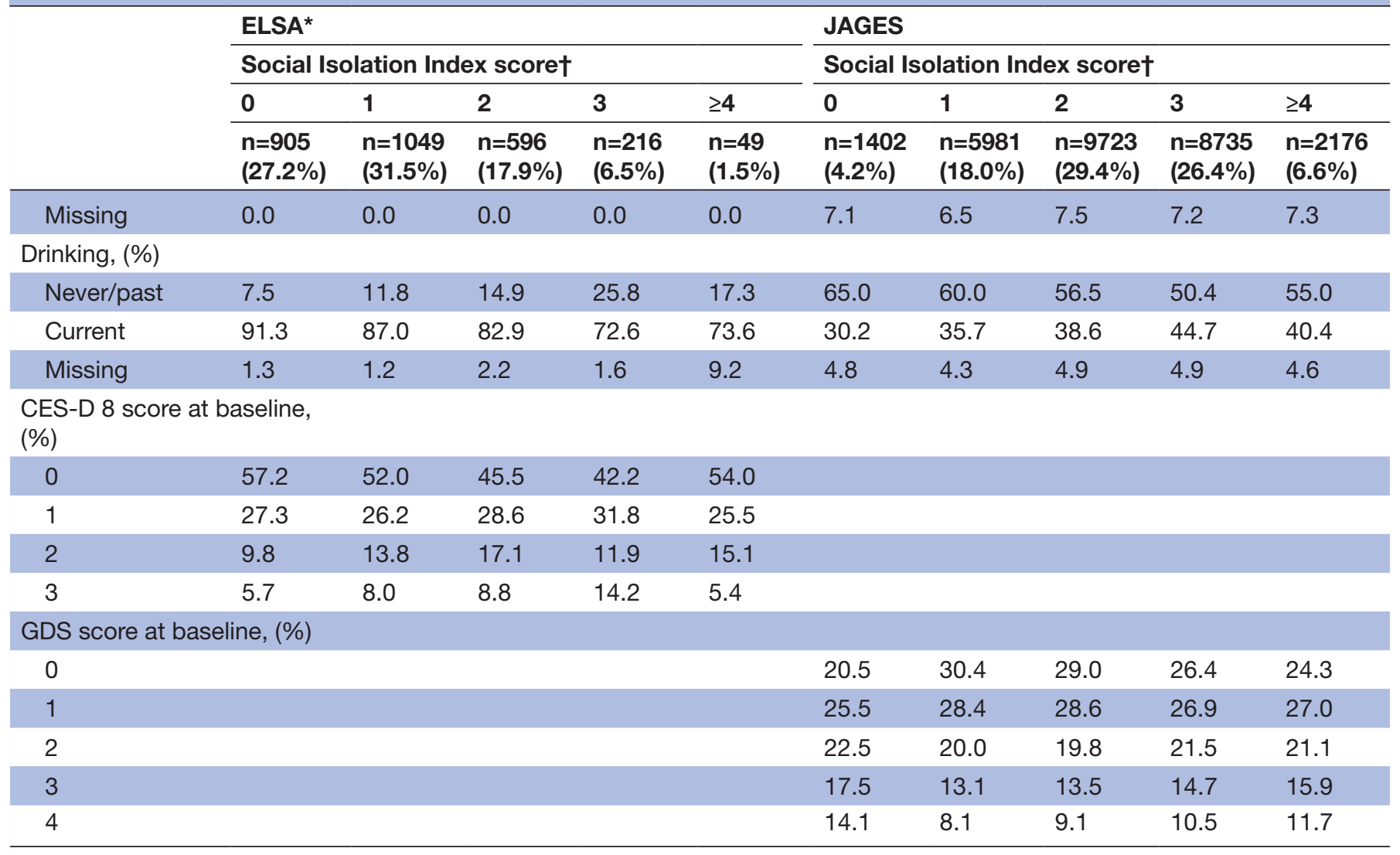

${ }^{*}$ ELSA data after sampling weight.

†Missing data: ELSA, $n=516$; JAGES, $n=5110$.

CES-D 8, eight items from the Centre for Epidemiologic Studies Depression Scale; ELSA, English Longitudinal Study of Ageing; GDS,

Geriatric Depression Scale; JAGES, Japan Gerontological Evaluation Study.

isolation was significantly associated with depression onset in both countries. Our results support previous longitudinal findings on social relationships and mental health among older adults in England ${ }^{37}$ and Japan. ${ }^{38}$ Using data frames that were similar with regard to assessment and covariates, we demonstrated that social isolation is a common risk factor for depression in England and Japan, despite country-specific cultural differences regarding social relationships. Thus, our results suggest that to safeguard the mental health of older adults, addressing social isolation is a global need.

The association between social isolation and depression was somewhat stronger in England than in Japan. These results are similar to a previous report concerning mortality among older adults in England and Japan. ${ }^{11}$ Although we cannot make direct comparisons due to variations in cohort follow-up periods and depression measurement, there are several possible reasons for this pattern of findings. The impact of social factors could differ depending on the group and society to which one belongs. This is best understood in the context of the concept of relative deprivation. ${ }^{39}$ In other words, higher levels of relative social isolation may induce greater psychological stress. A previous study showed that rich community ties and cohesion were protective factors for health but could have a negative effect on those who were not socially involved. ${ }^{40}$ Being isolated in a connected society such as the UK may represent a more severe condition, with a stronger negative impact on mental health.

Our results revealed that poor interaction with children was significant with regard to depression onset in Japan. In England, while the association was marginal, of the components of social isolation, poor interaction with children had the greatest effect. The lack of interaction with children could have an adverse effect on the mental health of older adults in both countries. Previous studies in England ${ }^{41}$ and $\operatorname{Japan}^{22}$ have reported that social support from children can contribute to alleviating depression, and our results point in the same direction. Older adults without children can be considered a vulnerable group, because adult children, in particular, are often the main source of positive social support for older parents. ${ }^{42}$ Older parents have certain expectations with regard to receiving support from their children, and situations wherein these expectations are not met may lead to depressive mood. ${ }^{43}$ However, a previous study reported no association between the presence of children and depression among older adults in the USA. ${ }^{22}$ Owing to strong spousal relationships in the USA, the effect of the presence of children might be relatively small. Thus, our study confirmed the adverse effects of poor interaction with children common to England and Japan, but international generalisability can only be established based on further research considering 
Table 2 Description of social isolation status and depression onset

\begin{tabular}{|c|c|c|c|}
\hline \multirow{2}{*}{\multicolumn{2}{|c|}{$\begin{array}{l}\text { ELSA }^{*} \\
\text { CES-D } 8 \text { score at follow-un }\end{array}$}} & \multicolumn{2}{|l|}{ JAGES } \\
\hline & & \multicolumn{2}{|c|}{ GDS score at follow-up } \\
\hline$<4$ & $\geq 4$ & $<5$ & $\geq 5$ \\
\hline $\begin{array}{l}n=3130 \\
(94.0 \%)\end{array}$ & $\begin{array}{l}n=201 \\
(6.0 \%)\end{array}$ & $\begin{array}{l}n=28671 \\
(86.5 \%)\end{array}$ & $\begin{array}{l}n=4456 \\
(13.5 \%)\end{array}$ \\
\hline
\end{tabular}

Social Isolation Index score, (\%)

\begin{tabular}{|c|c|c|c|c|}
\hline 0 & 27.5 & 13.5 & 4.4 & 3.0 \\
\hline 1 & 31.2 & 29.3 & 18.6 & 14.3 \\
\hline 2 & 17.9 & 18.9 & 29.8 & 26.3 \\
\hline 3 & 6.5 & 10.1 & 26.2 & 27.5 \\
\hline$\geq 4$ & 1.5 & 2.9 & 6.1 & 9.3 \\
\hline Missing & 15.4 & 25.3 & 14.8 & 19.7 \\
\hline \multicolumn{5}{|c|}{ Social Isolation Index sub-components, (\%) } \\
\hline Unmarried or living alone & 71.9 & 58.5 & 88.3 & 85.2 \\
\hline \multicolumn{5}{|l|}{ No } \\
\hline Yes & 28.1 & 41.5 & 10.2 & 12.7 \\
\hline Missing & 0.0 & 0.0 & 1.4 & 2.1 \\
\hline Poor interaction with children & 81.8 & 73.4 & 26.6 & 25.0 \\
\hline \multicolumn{5}{|l|}{ No } \\
\hline Yes & 12.5 & 14.7 & 71.7 & 72.9 \\
\hline Missing & 5.7 & 11.8 & 1.7 & 2.1 \\
\hline Poor interaction with relatives & 76.3 & 68.1 & 41.1 & 38.7 \\
\hline \multicolumn{5}{|l|}{ No } \\
\hline Yes & 17.3 & 18.6 & 54.4 & 56.0 \\
\hline Missing & 6.4 & 13.4 & 4.5 & 5.4 \\
\hline Poor interaction with friends & 72.2 & 66.0 & 37.1 & 31.2 \\
\hline \multicolumn{5}{|l|}{ No } \\
\hline Yes & 18.4 & 21.6 & 58.2 & 63.8 \\
\hline Missing & 9.4 & 12.4 & 4.6 & 5.0 \\
\hline No social participation & 61.7 & 46.3 & 75.0 & 63.9 \\
\hline \multicolumn{5}{|l|}{ No } \\
\hline Yes & 28.4 & 32.5 & 13.0 & 20.0 \\
\hline Missing & 10.0 & 21.2 & 11.7 & 16.1 \\
\hline
\end{tabular}

*ELSA data after sampling weight.

CES-D 8, eight items from the Centre for Epidemiologic Studies Depression Scale; ELSA, English Longitudinal Study of Ageing; GDS,

Geriatric Depression Scale; JAGES, Japan Gerontological Evaluation Study.

the cultural background of family relationships in individual countries.

Although traditionally Japan is a country in which adult children are expected to demonstrate reciprocity with their parents based on the strong family and kinship-based cultural background, ${ }^{44}$ in this study, the effect of interaction with children on depression was relatively modest. In recent years, with trends such as adult children commonly living apart from their parents after marriage ${ }^{45}$ and the development of public long-term care services for the ageing population, ${ }^{46}$ Japan's family system has become less traditional. Therefore, interaction with children may not be as essential to the health of older adults as before. However, despite these cultural transitions, we believe that interaction with children has some value with regard to preventing depression in old age in Japan.

Social participation was a strong protective factor for depression onset in Japan, whereas there was no association in England, although the OR was somewhat greater. Several previous studies have reported that social participation helps prevent depression onset. ${ }^{37} 47-49$ Our results pertaining to Japan support these reports. However, the protective effects of social participation on mental health vary depending on the type of organisation with which an individual is involved, ${ }^{48}$ 
Table 3 Association between social isolation and depression onset: multivariable logistic regression analysis

\begin{tabular}{|c|c|c|c|c|}
\hline & \multicolumn{2}{|l|}{ ELSA } & \multicolumn{2}{|l|}{ JAGES } \\
\hline & Crude OR $(95 \% \mathrm{Cl})$ & Adjusted OR (95\% Cl) & Crude OR $(95 \% \mathrm{Cl})$ & Adjusted OR (95\% Cl) \\
\hline \multicolumn{5}{|c|}{ Social Isolation Index score } \\
\hline 1 & $1.92^{* *}(1.19$ to 3.10$)$ & $1.68^{*}(1.02$ to 2.75$)$ & 1.14 (0.94 to 1.39$)$ & 1.10 (0.89 to 1.35$)$ \\
\hline 2 & $2.15^{\star \star}(1.28$ to 3.62$)$ & $1.77^{*}(1.03$ to 3.05$)$ & $1.32^{* *}(1.09$ to 1.60$)$ & 1.15 (0.94 to 1.40$)$ \\
\hline$\geq 4$ & $P$ for trend $<0.001$ & $P$ for trend $=0.015$ & $P$ for trend $<0.001$ & $P$ for trend $<0.001$ \\
\hline
\end{tabular}

Adjusted for age, gender, educational attainment, household equivalised income, present illness (cancer, heart disease, and stroke), self-rated health, smoking, drinking, and depression score at baseline (eight items from the Centre for Epidemiologic Studies Depression Scale for the ELSA and Geriatric Depression Scale for the JAGES).

${ }^{*} \mathrm{P}<0.05 ;{ }^{*} \mathrm{P}<0.01 ;{ }^{* * *} \mathrm{P}<0.001$.

ELSA, English Longitudinal Study of Ageing; JAGES, Japan Gerontological Evaluation Study.

the individual's attitude towards participation, ${ }^{48}$ and the duration $^{37}$ and frequency ${ }^{49}$ of participation. Regarding the present study, in the English context, the role of social participation in depression prevention might have been unidentifiable due to differences in the effects of these participation contexts. We took into account only social participation, without delving into specific types. Thus, the context of effective social participation, such as type, duration, and role in the organisation in both countries, requires further investigation. Despite these challenges, our findings suggest that in Japan, social isolation prevention measures based on the promotion of social participation could be beneficial for safeguarding the mental health of older adults.

This study has several strengths. First, it is the first crossnational population-level investigation of the association of social isolation with depression onset using a unified data frame. Second, by using two longitudinal datasets, we were able to examine the prospective association between social isolation and depression. Third, the use of large-scale data allowed us to detect the effects of relatively rare situations of severe social isolation.
However, certain limitations cannot be ignored. First, the measurement of depression in the two cohorts was not the same. Therefore, we could not directly compare depression onset in the two countries. However, these measurements were also used in a previous cross-national comparison study in England and Japan, ${ }^{28}$ and we were able to examine the association between social isolation and depression onset in both countries using the same data frame. Second, we used social support for the assessment of social contact for some items in order to be able to use the same SII. Therefore, cultural differences in expectations regarding the receipt of social support in both countries might have caused information biases. For instance, expectations regarding social support from relatives could originally have been higher in Japan, ${ }^{44}$ leading to overestimation of social isolation levels. Third, regarding the items of the SII, the questions and their response options in the ELSA and JAGES were not exactly the same, nor were they strictly authorised through procedures such as reverse translation and confirming reliability and validity. However, we believe it is certainly meaningful to evaluate social isolation using the same framework. Finally,

Table 4 Association between subcomponents of social isolation and depression onset: multivariable logistic regression analysis

\begin{tabular}{|c|c|c|}
\hline & ELSA & JAGES \\
\hline & Adjusted OR (95\% Cl) & Adjusted OR $(95 \% \mathrm{Cl})$ \\
\hline \multicolumn{3}{|c|}{ Social Isolation Index subcomponents (reference: none) } \\
\hline Poor interaction with children & $1.55 \dagger(1.00$ to 2.41$)$ & $1.09^{*}(1.01$ to 1.19$)$ \\
\hline Poor interaction with relatives & 1.24 (0.79 to 1.94$)$ & 1.04 (0.96 to 1.12$)$ \\
\hline No social participation & $1.22(0.80$ to 1.87$)$ & $1.28^{\star \star \star}(1.17$ to 1.40$)$ \\
\hline
\end{tabular}

Adjusted for age, gender, educational attainment, equivalent income, present illness (cancer, heart disease and stroke), self-rated health, smoking, drinking and depression score at baseline (eight items from the Centre for Epidemiologic Studies Depression Scale for the ELSA and Geriatric Depression Scale for the JAGES).

${ }^{*} \mathrm{P}<0.05 ;{ }^{* * *} \mathrm{P}<0.001 ; \dagger \mathrm{P}<0.1$.

ELSA, English Longitudinal Study of Ageing; JAGES, Japan Gerontological Evaluation Study. 
there were differences in study design in the data from the two cohorts, such as sampling method and follow-up period. We, therefore, made efforts to harmonise the data: those aged $\leq 64$, with dementia, and dependent in activities of daily living were excluded from the analysis. Moreover, the ELSA presents nationally representative population data, while the JAGES does not. However, the JAGES sample is representative of areas from a nationwide ageing study in which approximately one-fifth of all prefectures (9 out of 47) were enrolled. Even so, unlike the ELSA, analysis in the JAGES does not use sampling weights, which may lead to selection bias.

\section{CONCLUSION}

We examined the association between social isolation and depression onset among older adults in England and Japan, who experience different cultural contexts regarding social relationships, and found a significant association in both countries; we also observed that in England, poor interaction with children was marginally associated, and in Japan, poor interaction and lack of social participation were significantly associated with depression. Tackling social isolation must be prioritised to safeguard the mental health of older adults worldwide. Particularly in Japan, the promotion of interaction with children and social participation could be key factors in addressing social isolation.

\section{Author affiliations}

${ }^{1}$ Department of Social Science, Center for Gerontology and Social Science, National Center for Geriatrics and Gerontology, Obu, Japan

${ }^{2}$ Department of Public Health, Nagoya City University Graduate School of Medical Sciences and Medical School, Nagoya, Japan

${ }^{3}$ Faculty of Social Welfare, Nihon Fukushi University, Chita-gun, Japan

${ }^{4}$ Department of Oral Health Promotion, Tokyo Medical and Dental University Graduate School of Medical and Dental Sciences, Bunkyo-ku, Japan

${ }^{5}$ Division for Regional Community Development, Liaison Center for Innovative Dentistry, Tohoku University, Sendai, Japan

${ }^{6}$ Department of Epidemiology and Public Health, University College London, London, UK

${ }^{7}$ Faculty of Health and Sport Sciences, University of Tsukuba, Tokyo, Japan ${ }^{8}$ Department of Social Preventive Medical Sciences, Center for Preventive Medical Sciences, Chiba University, Chiba, Japan

${ }^{9}$ Cancer Control Center, Osaka International Cancer Institute, Osaka, Japan

${ }^{10}$ Department of Health Policy Science, Yamagata University Faculty of Medicine Graduate School of Medical Science, Yamagata, Japan

${ }^{11}$ Department of International and Community Oral Health, Tohoku University Graduate School of Dentistry School of Dentistry, Sendai, Japan

${ }^{12}$ Department of Gerontological Evaluation, Center for Gerontology and Social

Science, National Center for Geriatrics and Gerontology, Obu, Japan

\section{Twitter Noriko Cable @nkcable}

Acknowledgements We wish to express our deepest gratitude to the members in the Japan Gerontological Evaluation Study. We would also like to thank everyone who participated in the surveys.

Contributors All authors contributed to the conception and design of this study. Data collection was primarily conducted by MS, JA, NC, KO and KK. Analyses were performed by TN, MS, JA, TT, SK and TI. TN prepared the initial manuscript and MS, JA, NC, TT, SK, TI, KO, and KK significantly contributed to revising it. All authors read and approved the final manuscript.

Funding This work was supported by a grant from the Grants-in-Aid for Scientific Research (18KK0057, 19K24277) from the Japan Society for the Promotion of Science. The English Longitudinal Study of Ageing was developed by a team of researchers based at the University College London, NatCen Social Research, and the Institute for Fiscal Studies. The data were collected by NatCen Social
Research. The funding is currently provided by the National Institute of Aging (R01AG017644) and a consortium of UK government departments coordinated by the National Institute for Health Research. The Japan Gerontological Evaluation Study is supported by the Ministry of Education, Culture, Sports, Science and Technology-Japan-Supported Program for the Strategic Research Foundation at Private Universities (2009-2013), Japan Society for the Promotion of Science KAKENHI Grant Numbers (JP18390200, JP22330172, JP22390400, JP23243070, JP23590786, JP23790710, JP24390469, JP24530698, JP24683018, JP25253052, JP25870573, JP25870881, JP26285138, JP26882010, JP15H01972), Health Labour Sciences Research Grants (H22-Choju-Shitei-008, H24-Junkanki -Ippan007, H24-Chikyukibo-Ippan-009, H24-Choju-Wakate-009, H25-Kenki-Wakate-015, H25-Choju-Ippan-003, H26-Irryo-Shitei-003 [Fukkou], H26-Choju-Ippan-006, H27-Ninchisyou-Ippan-001, H28-chojulppan-002, H28-Ninchisho-Ippan-002, H30-Kenki-Ippan-006, H30-Junkankitou-Ippan-004), Japan Agency for Medical Research and Development (JP17dk0110017, JP18dk0110027, JP18Is0110002, JP18le0110009, JP19dk0110034), Research Funding for Longevity Sciences from the National Center for Geriatrics and Gerontology (24-17, 24-23, 29-42, 30-22, 20-40), Open Innovation Platform with Enterprises, Research Institute and Academia (OPERA, JPMJOP1831) from the Japan Science and Technology Agency, and a Research Grant from the Health Science Center Foundation (2019-2020).

The funding sources had no role in the study design, data collection and analysis, decision to publish or preparation of the manuscript.

Competing interests None declared.

Patient consent for publication Not required.

Ethics approval The ELSA investigators received ethical approval for all waves of the study from the National Health Service Research Ethics Committees under the National Research and Ethics Services (MREC/01/2/91). The JAGES protocols were approved by the Ethics Committee on the Research of Human Subjects at Nihon Fukushi University (10-05).

Provenance and peer review Not commissioned; externally peer reviewed.

Data availability statement Data may be obtained from a third party and are not publicly available. For the JAGES, all enquiries are to be addressed to the data management committee via email: dataadmin.ml@jages.net. All JAGES datasets have ethical or legal restrictions for public deposition because of the inclusion of sensitive information about the human participants. Regarding the ELSA, data are available in an open-access repository at https://www.data-archive.ac.uk/.

Supplemental material This content has been supplied by the author(s). It has not been vetted by BMJ Publishing Group Limited (BMJ) and may not have been peer-reviewed. Any opinions or recommendations discussed are solely those of the author(s) and are not endorsed by BMJ. BMJ disclaims all liability and responsibility arising from any reliance placed on the content. Where the content includes any translated material, BMJ does not warrant the accuracy and reliability of the translations (including but not limited to local regulations, clinical guidelines, terminology, drug names and drug dosages), and is not responsible for any error and/or omissions arising from translation and adaptation or otherwise.

Open access This is an open access article distributed in accordance with the Creative Commons Attribution 4.0 Unported (CC BY 4.0) license, which permits others to copy, redistribute, remix, transform and build upon this work for any purpose, provided the original work is properly cited, a link to the licence is given, and indication of whether changes were made. See: https://creativecommons.org/ licenses/by/4.0/.

\section{ORCID iDs}

Taiji Noguchi http://orcid.org/0000-0001-9165-5501

Masashige Saito http://orcid.org/0000-0002-3997-3884

Jun Aida http://orcid.org/0000-0002-8405-9872

Noriko Cable http://orcid.org/0000-0001-5478-1760

Taishi Tsuji http://orcid.org/0000-0002-8408-6619

Shihoko Koyama http://orcid.org/0000-0002-7786-4910

Takaaki lkeda http://orcid.org/0000-0003-4325-4492

Ken Osaka http://orcid.org/0000-0001-6885-9514

Katsunori Kondo http://orcid.org/0000-0003-0076-816X

\section{REFERENCES}

1 Townsend P. The family life of old people: an investigation in East London. Sociol Rev 1955;3:175-95.

2 Holt-Lunstad J, Smith TB, Layton JB. Social relationships and mortality risk: a meta-analytic review. PLoS Med 2010;7:e1000316. 
3 Valtorta NK, Kanaan M, Gilbody S, et al. Loneliness and social isolation as risk factors for coronary heart disease and stroke: systematic review and meta-analysis of longitudinal observational studies. Heart 2016;102:1009-16.

4 Livingston G, Sommerlad A, Orgeta V, et al. Dementia prevention, intervention, and care. Lancet 2017;390:2673-734.

5 Leigh-Hunt N, Bagguley D, Bash K, et al. An overview of systematic reviews on the public health consequences of social isolation and loneliness. Public Health 2017;152:157-71.

6 Santini ZI, Koyanagi A, Tyrovolas S, et al. The association between social relationships and depression: a systematic review. J Affect Disord 2015;175:53-65.

7 Kawachi I, Berkman LF. Social ties and mental health. J Urban Health 2001;78:458-67.

8 Sivertsen H, Bjørkløf GH, Engedal K, et al. Depression and quality of life in older persons: a review. Dement Geriatr Cogn Disord 2015;40:311-39.

9 Chen C-M, Mullan J, Su Y-Y, et al. The longitudinal relationship between depressive symptoms and disability for older adults: a population-based study. J Gerontol A Biol Sci Med Sci 2012;67:1059-67.

10 World Federation for Mental Health. Depression: a global crisis. world mental health day, October 10 2012, 2012. Available: https:// www.who.int/mental_health/management/depression/wfmh_paper_ depression_wmhd_2012.pdf [Accessed 7 Feb 2020].

11 Saito M, Aida J, Cable N, et al. Cross-National comparison of social isolation and mortality among older adults: a 10-year follow-up study in Japan and England. Geriatr Gerontol Int 2021;21:209-214.

12 HM Government. A connected Society: a strategy for tackling loneliness - laying the foundations for change, 2018. Available: https://assets.publishing.service.gov.uk/government/uploads/ system/uploads/attachment_data/file/750909/6.4882_DCMS Loneliness_Strategy_web_Update.pdf [Accessed 12 Oct 2020].

13 Muramatsu N, Akiyama H. Japan: super-aging Society preparing for the future. Gerontologist 2011;51:425-32.

14 National Institute of Population and Social Security Research. Household projections for Japan. Available: http://www.ipss.go.jp/ pp-ajsetai/e/hprj_98/hprj_98.html [Accessed 12 Oct 2020].

15 Murayama $\mathrm{H}$, Shibui $\mathrm{Y}$, Fukuda $\mathrm{Y}$, et al. A new crisis in Japan-social isolation in old age. J Am Geriatr Soc 2011;59:2160-2.

16 Organisation for Economic Co-operation and Development. Society at a glance: OECD social indicators. Paris OECD Publishing; 2005.

17 Takagi E, Silverstein M. Intergenerational coresidence of the Japanese elderly:are cultural norms proactive or reactive? Res Aging 2006;28:473-92

18 Knight BG, Robinson GS, Flynn Longmire CV, et al. Cross cultural issues in caregiving for persons with dementia: do familism values reduce burden and distress? Ageing Int 2002;27:70-94.

19 Knight BG, Sayegh P. Cultural values and caregiving: the updated sociocultural stress and coping model. J Gerontol B Psychol Sci Soc Sci 2010;65B:5-13.

20 Cabinet Office. International comparative survey on the life and awareness of the elderly in 2015, 2015. Available: https://www8.cao. go.jp/kourei/ishiki/h27/zentai/index.html [Accessed 30 Jan 2021].

21 Aida J, Cable N, Zaninotto P, et al. Social and behavioural determinants of the difference in survival among older adults in Japan and England. Gerontology 2018;64:266-77.

22 Sugisawa $\mathrm{H}$, Shibata $\mathrm{H}$, Hougham GW. The impact of social ties on depressive symptoms in U.S. and Japanese elderly. J Soc Issues 2003;58:785-804.

23 Cable N, Chandola T, Lallukka T, et al. Country specific associations between social contact and mental health: evidence from civil servant studies across Great Britain, Japan and Finland. Public Health 2016;137:139-46.

24 Santini ZI, Jose PE, York Cornwell E, et al. Social disconnectedness, perceived isolation, and symptoms of depression and anxiety among older Americans (NSHAP): a longitudinal mediation analysis. Lancet Public Health 2020;5:e62-70.

25 The Commonwealth Fund. International profiles of health care systems, 2017. Available: https://www.commonwealthfund.org/sites/ default/files/documents/__media_files_publications_fund_report 2017_may_mossialos_intl_profiles_v5.pdf [Accessed 12 Oct 2020].

26 Kondo K. Progress in aging epidemiology in Japan: the JAGES project. J Epidemiol 2016;26:331-6.
27 Steptoe A, Breeze E, Banks J, et al. Cohort profile: the English longitudinal study of ageing. Int J Epidemiol 2013;42:1640-8.

28 Cable N, Chandola T, Aida J, et al. Can sleep disturbance influence changes in mental health status? Longitudinal research evidence from ageing studies in England and Japan. Sleep Med 2017;30:216-21.

29 Marmot M, Banks J, Blundell R. Health, wealth and lifestyles of the older population in England: the 2002 English longitudinal study of ageing. London: Institute for Fiscal Studies, 2003.

30 Wada T, Ishine M, Kita T, et al. Depression screening of elderly community-dwelling Japanese. J Am Geriatr Soc 2003;51:1328-9.

31 Gallagher D, Kiss A, Lanctot K, et al. Depressive symptoms and cognitive decline: a longitudinal analysis of potentially modifiable risk factors in community dwelling older adults. J Affect Disord 2016;190:235-40.

32 Burke WJ, Roccaforte WH, Wengel SP. The short form of the geriatric depression scale: a comparison with the 30-item form. J Geriatr Psychiatry Neurol 1991;4:173-8.

33 Ikeda T, Cable N, Saito M, et al. Association between social isolation and smoking in Japan and England. J Epidemiol 2020. doi:10.2188/ jea.JE20200138. [Epub ahead of print: 08 Aug 2020].

34 Tsuji T, Saito M, Ikeda T, et al. Change in the prevalence of social isolation among the older population from 2010 to 2016: a repeated cross-sectional comparative study of Japan and England. Arch Gerontol Geriatr 2020;91:104237.

35 Shankar A, McMunn A, Banks J, et al. Loneliness, social isolation, and behavioral and biological health indicators in older adults. Health Psychol 2011;30:377-85.

36 White IR, Royston P, Wood AM. Multiple imputation using chained equations: issues and guidance for practice. Stat Med 2011;30:377-99

37 Cruwys T, Dingle GA, Haslam C, et al. Social group memberships protect against future depression, alleviate depression symptoms and prevent depression relapse. Soc Sci Med 2013;98:179-86.

38 Koizumi Y, Awata S, Kuriyama S, et al. Association between social support and depression status in the elderly: results of a 1-year community-based prospective cohort study in Japan. Psychiatry Clin Neurosci 2005;59:563-9.

39 Smith HJ, Pettigrew TF, Pippin GM, et al. Relative deprivation: a theoretical and meta-analytic review. Pers Soc Psychol Rev 2012;16:203-32.

40 Amemiya A, Saito J, Saito M, et al. Social capital and the improvement in functional ability among older people in Japan: a multilevel survival analysis using JAGES data. Int J Environ Res Public Health 2019;16:1310.

41 Stafford M, McMunn A, Zaninotto P, et al. Positive and negative exchanges in social relationships as predictors of depression: evidence from the English longitudinal study of aging. J Aging Health 2011;23:607-28.

42 Koropeckyj-Cox T. Loneliness and depression in middle and old age: are the childless more vulnerable? J Gerontol B Psychol Sci Soc Sci 1998;53:S303-12.

43 Lee GR, Netzer JK, Coward RT. Depression among older parents: the role of intergenerational exchange. J Marriage Fam 1995;57:823-33.

44 Brown JW, Liang J, Krause N, et al. Transitions in living arrangements among elders in Japan: does health make a difference? J Gerontol B Psychol Sci Soc Sci 2002;57:S209-20.

45 Takagi E, Silverstein M. Purchasing piety? Coresidence of married children with their older parents in Japan. Demography 2011;48:1559-79.

46 Tsutsui T, Muramatsu N. Care-needs certification in the long-term care insurance system of Japan. J Am Geriatr Soc 2005;53:522-7.

47 Takagi D, Kondo K, Kawachi I. Social participation and mental health moderating effects of gender, social role and rurality. BMC Public Health 2013;13:701.

48 Tomioka K, Kurumatani N, Hosoi H. Positive and negative influences of social participation on physical and mental health among community-dwelling elderly aged $65-70$ years: a cross-sectional study in Japan. BMC Geriatr 2017;17:111.

49 Choi E, Han K-M, Chang J, et al. Social participation and depressive symptoms in community-dwelling older adults: emotional social support as a mediator. J Psychiatr Res 2020. doi:10.1016/j.jpsychires.2020.10.043. [Epub ahead of print: 30 Oct 2020]. 